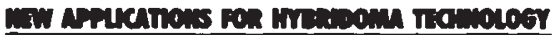 MONOCLONAL ANTBODIES: EMERGING PRODUCT CONCEPTS FOR AGRICULTURE AND FOOD
}

Tr $\mathrm{n}$ this article we discuss an exciting product concept for developing indicators, diagnostics, and possibly therapeutic tools for the agricultural and food industries. We have made a rough prioritization of the merits, the feasibility, and the economics of each of the new product concepts. The basis for this enticing development springs from the rapid progress made in the science of immunology. More specifically, this article discusses the development of products that could evolve through the use of monoclonal antibodies.

The analysis is based on a Battelledeveloped research method for bringing technology to the marketplace. The article presents the results of the first stage of this method. We have limited ourselves to the agricultural and food industries in the U.S. However, the general guidelines and concepts (obviously with some exceptions) should be generally applicable to other developed nations with intensive agricultural production methods.

The Technology: Production of Monoclonal Antibodies

An antibody is an immunoglobulin that reacts, or binds, with a specific oreign substance known as the antigen. Most of these reactions are extremely specific, i.e., a one-antigen/ one-antibody relationship. However, the immune response of the animal generally results in a population of antibodies with different antigenic specificities. Monoclonal antibody techniques overcome this problem.

The pioneering research behind hybridoma technology is less than 10 years old. In 1975, Cesar Milstein and Georges Kohler published their protocol for production of pure antibodies against red blood cells. The production method for monoclonal antibodies has changed relatively little from the first experiments. Myeloma tumor cells, which are capable of replicating endlessly in the laboratory under specific culture conditions, are fused with splenocytes, a type of lymphocyte, from mice that have been immunized with an antigen. The resulting "hybridoma cells" are capable of both producing antibodies and

nence I Simplified approach to monoclonal antibody production.

growing continuously in culture. The hybridoma cells are isolated and grown in separate colonies, i.e., cloned, and the clones producing the desired antibody are selected and grown in quantity. The antibodies produced by these clones are known as monoclonal antibodies (Fig. 1).

After the initial selection of the desired hybridoma clone, monoclonal antibodies can be produced in culture. Alternatively, cells from the desired hybridoma can be injected into the peritoneal cavity of a mouse, producing a tumor. The tumor cells secrete large quantities of antibody into a serum-like Huid called tumor ascites fluid. Mice carrying these hybridoma tumors are periodically "tapped" for the antibodies.

The advantage of using live mice over cell culture production is the higher yields of antibodies $(100 \mathrm{mil}$ lion cells $/ \mathrm{ml}$ of ascites fluid versus 10 million cells $/ \mathrm{ml}$ of culture fluid). Both systems, however, require expensive separation and purification processes to obtain a concentrated antibody preparation. A disadvantage of the live mouse process is that the mouse's own immune system may become sensitized to the antibodies, resulting in production of antibodies against the hybridoma and eventual destruction of the colony. We make the assumption in this article that, even 
though difficult technical problems may exist, cost-effective large scale production methods for monoclonal antibody production will be developed.

\section{Applications of Monoclonal Antibodies}

The ability to obtain pure antibodies specific for individual antigenic determinants resulted in a rapid proliferation of suggested applications for monoclonal antibodies. Scientists worldwide have applied hybridoma technology for the production of monoclonal antibodies against many antigens derived from bacteria, viruses, hormones, parasites, and various chemicals. Although the age of most commercial monoclonal antibodybased applications can be counted in months, these products captured an estimated market of almost $\$ 15$ million in 1982. The vast majority of the products are in vitro diagnostic kits marketed by several small biotechnology firms. These companies (e.g., $\mathrm{Hy}$ britech, Centocor and Genetic Systems) are being joined in the marketplace by larger and more established firms in the diagnostic and health fields such as Abbott, Johnson and Johnson, Syva Corp., Warner Lambert and Becton Dickinson. As the antibody production processes are improved and new products are introduced into the marketplace, sales of monoclonal antibody-based products could top $\$ 200$ million by the mid-1980's.
As mentioned above, commercial applications of monoclonal antibodies currently are limited to the health care markets. In particular, emphasis has been placed on diagnosis of a variety of bacterial and viral diseases, on blood and tissue typing, and on assays for several hormones and enzymes whose presence in the blood or urine can itself be used as a diagnostic (e.g., for pregnancy or cancer of a particular organ). Future applications for monoclonal antibodies in the health area include a variety of therapeutic and diagnostic products.

\section{Monoclonal Antibody Development in the Agriculture and Food \\ Industries}

Battelle Columbus has identified potential applications of the monoclonal antibody technology in the agricultural and food industries. The possible applications are presented in Table 1. Undoubtedly, other product concepts could be developed. It is interesting to note the overlap in some of the products' concepts. For example, detection of aflatoxin compounds could occur either in the field, at grain collection points, or at food and feed processors. In fact, for most of the product concepts, monoclonal antibody devices could be used at a number of points throughout the distribution system. Also, it is conceivable that a number of different customers (farmers, soil test agents, grain merchandisers, and food processors) would be interested in using the technology.

Where in the distribution system the monoclonal antibodies products will be used will largely determine the relative market size of the products. Therefore, we see a very complex marketing situation developing. While there are a great number of farmers who could use, and conceivably make up a very large market for, an aflatoxin detection device, it may not make the most sense for individual farmers to perform the test even though the technology may be amenable to on-farm use. The relatively low frequency of occurrence of aflatoxin (not ignoring its severity) indicates that it may be most logical to use it at grain collection points as opposed to on-the-farm. Given the complex issues involved, one can see the necessity for conducting a thorough techno-economic evaluation prior to initiating laboratory studies.

The product concepts listed in Table 1 were qualitatively ranked against a number of criteria. The criteria for ranking are noted in Table 2. It should be recognized that this is a first cut ranking; additional technical and economic work is required. Technical feasibility for all concepts at this stage of the analysis is assumed; in actuality this may turn out not to be the case. Also, we do not consider processability, production costs, etc. For example, the ability to develop reusable monoclonal products obviously would have a large bearing on the market size of the

TABLE 1 Selected Potential Applications of Monoclonal Antibodies in Agriculture and Food Industries.

\section{Agriculture}

Sexing Spermatazoa (X versus Y) for Livestock Breeding

Sexing Embryos For Livestock Breeding

Estrus and Ovulation Detection

Vaccine Development

Detection and Levels of Mycotoxins/Various Contaminants/ Parasites in Milk, Meat, Feed, Grains, etc.

Plant Disease Organism Isolation and Levels

Pesticide (especially Herbicide) Residues

Crop Maturity

\section{Food}

Food Product (Nutritional Quality)

Detection of Pathogens and Other Contaminants (Chemical, Antibiotic Residues for Example)

Package Security
Improved herd or flock productivity; long a research goal Improved herd productivity; 50 percent of embryo transfers now failures (dairy operations want females; beef operations want males)

Improved efficacy in artificial insemination and embryo transfer

Injection of antibodies directly precludes necessity of waiting for antibody production against antigen vaccine. Could be highly specific especially for very young livestock.

Various possibilities: e.g., detecting Salmonella in poultry feed, detecting mycotoxin or antibiotic residues in milk, detecting Trichinella in swine.

Could replace costly and not-very-timely soil tests. Could be especially valuable for symptomless viral diseases in high valued crops such as strawberries. Could enhance efficacy of fungicides applications.

At times, farmers are precluded from specific crop rotations due to previous crop year herbicide applications. Product could determine presence of residues and possibly levels; enhanced efficacy.

To determine optimal harvesting period. Probably most applicable in high valued crops, but also for hays and forages (e.g., alfalfa).

Aid to optimizing processing and packaging technologies: freshness indicator.

Protection of human safety; cost-effective and immediate.

Tamper-resistance. Source: Battelle Columbus Division. 
products. More detailed analyses are required prior to investment decisions. The exercise, nonetheless, points out the types of information required and the influence of individual criteria on the decision process. The results of Battelle's application of the criteria to the product concepts are shown in Table 3.

One procedure for estimating market potential and critical market factors is illustrated here for a monoclonal antibody kit for detection of aflatoxin presence in seeds/grains (principally corn and peanuts). The qualitative ranking for this product concept was moderately encouraging $(+$, Table 3$)$.

Indicators of potential market size for the aflatoxin detection kit are noted in Table 4. The factors influencing market development include proper market research, investigation of market channels and any regional aspects, significant barriers to entry, the financial and political venture structure, and regulatory aspects.

It is also necessary to look at constraints to commercialization. Undoubtedly there is a great deal of technical research and development required. Also, the infrastructural use patterns in the agricultural and food industries are such that they need to be taken into consideration. Other possible constraints to commercialization include regulatory clearances, sophistication of the device, safety and health care considerations, and, of course, the perceived benefit of the technology. These issues would be addressed in the next phase of market research and development.

\section{The Future}

The use of monoclonal antibody

TABLE 2 Criteria Used for First-Level Screening of Possible Monoclonal Antibody Product Concepts.

Potential Market Size-Conceptually represented by equation: Market Size = [(Number of Users) (Number of Uses/User/Year) (\$ Price/Use)]. Larger Sized Markets Better.

Availability and Cost of Alternative Competing Technology-Generally, the wide availability of one or more low-cost technologies competing with a monoclonal product would make the monoclonal product less attractive.

Market Requirement (Need) for Less-Sophisticated Use Technology-Monoclonal antibody products should be relatively easy to use, and perhaps could be used in infield applications. A need for a less sophisticated method of use should make a monoclonal product more attractive.

Management System and Target Product Value-Monoclonal antibody products (all other things being equal) should be more amenable to use in intensively managed systems and for products with relatively high product values. For example, a monoclonal livestock product should fit better with broiler production (a highly managed system) as opposed to a brood cow operation (a less intensively managed system). Likewise, a product would be ranked higher if used in grape production (high valued crop) as opposed to field corn production (lower valued crop).

Time-Urgent Applications-Monoclonal antibody products, in general, should be faster than most competing technologies. Monoclonal products should have better success where there is a necessity for quick response.

Regulatory Interaction/Government Agency Approval-Some monoclonal products may require FDA or other agency approval for use in certain applications. Such approval requirements typically add considerable time and monetary investment before commercialization. Generally, agency approval requirements would lead to a lower ranking of a particular monoclonal product concept. On the other hand, regulatory requirements that diagnostic tests be performed may in fact lead to larger markets for some monoclonal uses. For examples, live imported animals now are required by law to be quarantined; a monoclonal product that immediately determines the presence or lack of transmittable disease would encourage the product's use.

Source: Battelle Columbus Division

technology in the agricultural and food industries is an exciting concept, and worthy of increased attention. A number of product concepts have been illustrated; undoubtedly there are other good ideas.

The future of the area depends, in part, upon the success achieved with monoclonal products in the health care field, typically a higher valueadded product area. Many technical obstacles still need to be overcome.
Specifically, some of the technical disadvantages (and, therefore, R\&D opportunities) are:

- Antibody yields are relatively low with existing in vivo culturing technology. R\&D is underway in enhancing efficiency of separation and in vitro culturing methods. Microencapsulation of hybridoma cells is another approach, as is making monoclonal antibody products reusable.

TABLE 3 Ranking of Monoclonal Antibody Product Concepts.

Monoclonal Product Concepts

Criteria

\section{Agriculture}

Sexing Spermatazoa

Sexing Embryos

Estrus/Ovulation

Detection

Vaccines

Mycotoxin Detection

Plant Disease Detection

Pesticide Residue Detection

Food

Quality

Contamination

Package Security

$\begin{array}{cc}+ & ++ \\ + & ++ \\ ++ & - \\ ++ & - \\ + & + \\ ++ & + \\ + & +\end{array}$

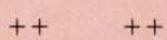

$++$

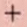

$-$

$$
++
$$

$+$

0

+
+
-

+
+
-

$$
++
$$$$
0
$$$$
++
$$$$
++
$$

$$
++
$$$$
++
$$

$$
+
$$$$
++
$$$$
0
$$$$
0
$$$$
+
$$$$
++
$$$$
++
$$$$
+
$$

$+$

0
+
0

\section{Key:* \\ $++=$ Situation Believed Highly En- couraging to Development of Sucessful Product \\ $+=$ Situation Believed Moderate- ly Encouraging to Develop- ment of Successful Product \\ $0=$ Situation Unknown, or Be- lieved Not to Influence Suc- cess \\ - = Situation Believed Moderate- ly Discouraging to Successful Product \\ -. = Successful, defined from standpoint of private invest- ment (e.g., large market, etc) as opposed to public benefit or technical achievability}


TABLE 4 Indicators of Potential Market Size for Case Study-Aflatoxin Detection Kit.

Current Year's Weather and Insect Infestation Patterns by Region-Mycotoxin occurrence in crop commodities is highly dependent upon the incidence of stress inducing weather and levels of insect damage. Aflatoxin is limited primarily to the southern United States, while the Fusarium-produced trichothecenes are found mainly in the Corn Belt and in Canada.

Amount of Crop Commodities Affected-Corn and peanuts are the crops with the most severe mycotoxin problems, although mycotoxins are also found in cottonseed, sorghum, rice, pecan, and several other crops. Year to year incidence varies dramatically but violative levels of mycotoxin may be found in over 80 percent of certain commodities in a given region in bad years. This potential for large losses has stimulated regular testing for mycotoxins by the FDA and private industry alike.

Frequency of Mycotoxin Sampling (Regional)-Varies with regulatory agency and product. The FDA spot checks processed food as part of their quality assurance program. The USDA tests all shipments of peanuts but relatively few of other commodities. Some states require the testing of products such as milk.

Competitive Technology and Costs-Current assay procedures involve sophisticated laboratory techniques using thin layer or high performance liquid chromatography. Costs range from $\$ 20$ to over $\$ 40$ per sample.

Ease of Use and Cost of Monoclonal Product-Monoclonal antibody-based tests for the simple presence of mycotoxins could be conducted in-field or at commodity storage points with more accuracy than current fluorescence techniques. Quantifying levels of mycotoxins should be technically feasible but tests may be more involved.

Source: Battelle Columbus Division.

- Antigenic determinants can change over time through natural mutation, especially in viral and bacterial organisms. Therefore, a monoclonal antibody product successful for one strain of Salmonella may not be successful over time or for another strain.

This article has attempted to lay the groundwork for developing a systematic approach to isolating sound product concepts in the agricultural and food area. Several product ideas appear to hold substantial merit, and are worthy of being carried forward to the next stage of market assessment and development.

R. L. Gatz, B. A. Young, T. J. Facklam, and D. A. Scantland are research and marketing analysts with Battelle Columbus Division, $\mathrm{OH}$.

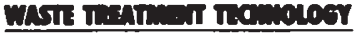

\section{ECONOMIC MOTIVES FOR MANAGING THE COMPOSTNG MICROBLAL ECOSYSTEM}

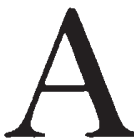

n old biotechnology, composting, has recently come into widespread use as a - sewage sludge treatmen process. (See Review Article, p. 347.) North American cities composting at least a sizeable portion of their sludge (or soon to do so) include Washing ton, DC; Philadelphia, PA; Camden, NJ; Columbus, and Akron, $\mathrm{OH}$; Bangor, ME; Los Angeles, CA; Key West, FL; Windsor, Ontario.

Composting can treat sewage sludge, and other materials such as municipal refuse and pharmaceutical wastes, because it produces a process residue which is relatively stable, dry, low in weight and volume, and sanitary, i.e., more manageable. At minimum this results in improved storability and transportability, and a reduced volume for ultimate disposal, thereby extending the recipient landfill's useful life. Moreover, landfill regulations might ban certain wastes which can be made acceptable through composting.

A higher goal is conversion of the waste to a useful product. The traditional product is compost, an organic soil amendment, but other possible uses of the process residue are as a landfill cover material, and as a biomass-derived (solid) fuel. The latter possibility results from composting's powerful capacity, when properly managed, to vaporize water, leaving a dry residue.

Regardless, resource recovery can be expected to defray only a small part of the processing costs, and composting, like other waste treatment technologies, is a money-consuming operation. Based on experience at several of the cities noted above, a rough estimate of the capital cost is $\$ 12$ million for a $25-100 \mathrm{dry}$ ton/day sewage sludge facility; the net operating cost is roughly $\$ 100 /$ dry ton. However, this experience is based on empirical approaches to design and control which fail to consider man-

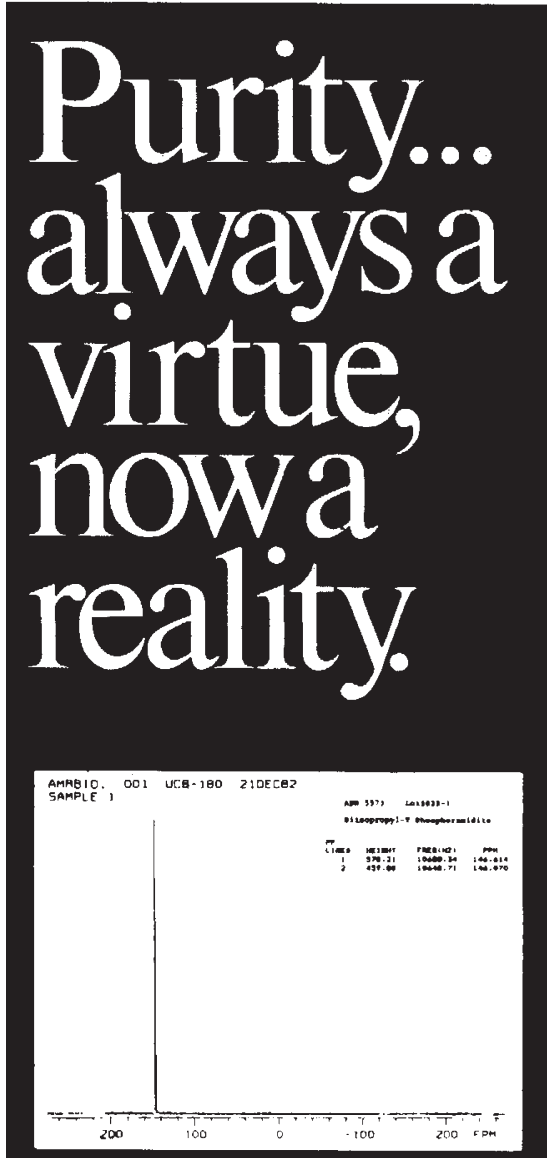

When you need purity and product integrity, you need American BioNuclear.

We synthesize each Nucleoside, Reagent and Phosphoramidite under the strictest production protocols. Then we test and retest with the finest state-of-the-art techniques and analytical instruments to insure the purest compounds possible.

At American BioNuclear

we are more than a laboratory. we are manufacturing chemists who take raw materials and transform them into fine organic and biochemical compounds.

American BioNuclear.

precision organic and biochemical materials for DNA synthesis.

American BioNuclear

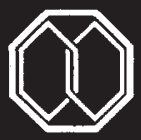

tion Horton Street

Emerville. (A 9 dols

$415 / 0.52-4.460$

Circle No. 96 on Reader Service Card 